\title{
Cultural Environment as a Potential for Society Renewal
}

\author{
${ }^{1}$ Zenija Kruzmetra, ${ }^{2}$ Dina Bite, ${ }^{3}$ Ginta Kronberga \\ $1,2,3$ Institute of Social Sciences and Humanities, Faculty of Economics and Social \\ Development, Latvia University of Agriculture
}

\begin{abstract}
The renewal of society is a broad term in its original sense but in the context of the article, it is linked with issues of depopulation, territorial polarization, and shrinking processes in Latvia. One of the "hot points" for local governments has been finding ways to attract people and promote the development of rural territories for the past decades. Both theoretical and practical solutions for maintaining rural society and promoting the renewal of society are the development of the cultural environment. Cultural activities directly affect public participation, cooperation among the population, the development of creativity, and promotion of inclusive society, health and society renewal. As recent investigations show, cultural environment is broadly developing in rural territories of Latvia. The research of cultural environment as a potential for the renewal of society of Latvia is a novelty due to the beginning of the National Research Program for the period 2014-2017 funded by the Government of Latvia (EKOSOC LV projects 5.2.4., 5.2.8.). The aim of the article is to analyze cultural environment as a potential for renewal of society in rural territories of Latvia. The research object is planning and development documents of local governments, different agents of rural territories. The results of the study reveal development of cultural environment in rural regions in Latvia. However, these practices are fragile yet and need support. They can bring forth new social and economic structures and serve as promoters of the smart development of rural territories in Latvia. For this reason, local governments should create their strategies to appreciate and support cultural activities as their potential for renewal of rural society.
\end{abstract}

Keywords: Cultural environment, Renewal of society, Smart development of territory

\section{INTRODUCTION}

Society renewal is a pressing need of Western societies determined by demographic processes (aging, negative natural growth, migration, depopulation) that cause the loss of population in certain areas. Consequently, the essential goal of territorial development is to fight the depopulation. The indirect, secondary activities which are more focused on social renewal are not less important than the primary, direct activities which concern demographic renewal of society. The social renewal includes a variety of dimensions - rising of human and social capital, housing, health, living and working environment, etc. The renewal of society is also determined by a cultural environment that includes both tangible and intangible cultural phenomena as well as various social aspects. Cultural activities are linked to public participation, cooperation among the population, creativity, and inclusive society.

\section{LITERATURE REVIEW}

A number of scholars point out strong statistical associations between life expectancy and cultural development, robust association between cultural environment and psychological well-being (Konlaan et al., 2000; Grossi et al. 2011, 2013; Crociata, Agovino, and Sacco, 2014; Raud, 2009). It is related to the smart development of territory that means systemic vision to the development of territory, integration, decentralized public management, inclusion, and participation, innovations, knowledge and relational capital (Smart Territorial Development, 2014) (see Figure 1). 


\section{Cultural \\ Environment}

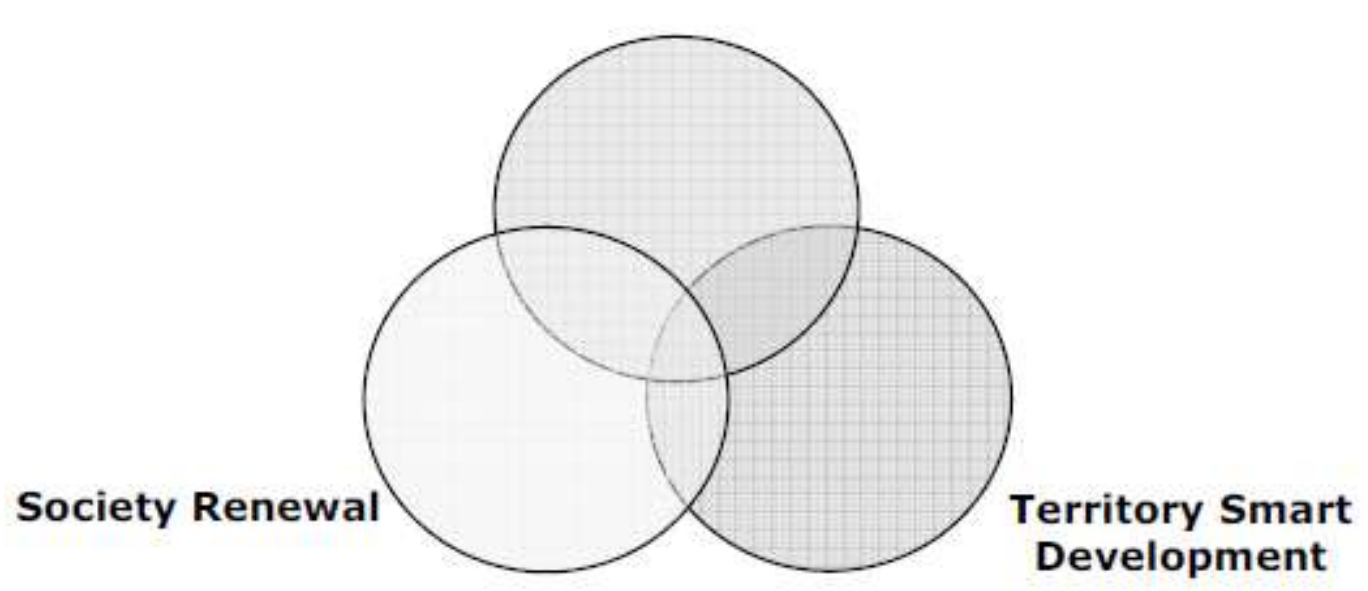

Figure 1: Interaction among population, cultural environment, and smart development of territory

Source: Authors' construction based on theoretical statements

Authors of the paper are seeking links between cultural activities and renewal of society in Latvia both in development strategies of local governments and in real practices of local inhabitants. Authors assume that cultural environment has a significant potential of renewal processes.

Authors base this assumption on idea by Rudolf Steiner that the basic values of renewal of society are free cultural activities, individual responsibility and freedom to perform individual aims; "the only way to renewal, to a healthy economy and healthy system of justice, is to create free space for the good impulses and aspirations living in humans to come to the surface" (Steiner, 2000; Williams, 2008; Matherne, 2005 et al.). Renewal of society includes the creation of new social practices that inspire and maintain individual and collective ability to cope with current local problems. It includes developing the capacities of what will be most needed in society and the new economy - creativity, adaptability, critical thinking and the ability to communicate and collaborate (Institute for Social Renewal, 2013).

The renewal of society is also linked with the cultural environment preservation and development as one of its affecting dimensions. Cultural heritage is environmentally creative (Concept Study, 2012). Special attention to the significance of cultural environment in development process started in 2000. Through differentiating of cultural development from social development, focusing on local development scientists have considered culture to be a factor of sustainable development at both national and international levels (Duxbury, Jeannotte, 2012).

The Cultural environment has been defined in the theoretical literature as a set of interdependent and interconnected systems and resources. As with openness applied to resources, openness concerning a community describes capacity to relate to that community as a contributor or user of resources that partially comprise the cultural commons. Theoretical focus on constructed cultural commons emerges from the proposition that cultural production is an inherently social phenomenon, taking place over a wide range of scales and within a complex, overlapping variety of formal and informal institutional structures (Madison, Frischmann and Strandburg, 2010). Therefore, cultural environment refers to an Environment created by human activity and through interaction between mankind and the natural environment. Innovation and creativity are matters of governance of a highly social cultural Environment. Natural resources, typically, are given. Although the natural environment is given and not made by humans, it is continuously and unavoidably affected by humans and, in a sense, made and remade and unmade with irreversible consequences through those interactions. And although humans always make the cultural environment, it is inherited, subject to considerable path 
dependencies that can have irreversible consequences and contingent on human interactions with the physical environment (Madison, Frischmann and Strandburg, 2010). That way local governments and local people are responsible for using of natural and other given resources as well as for creation other economic, social, cultural resources (see Figure 2).

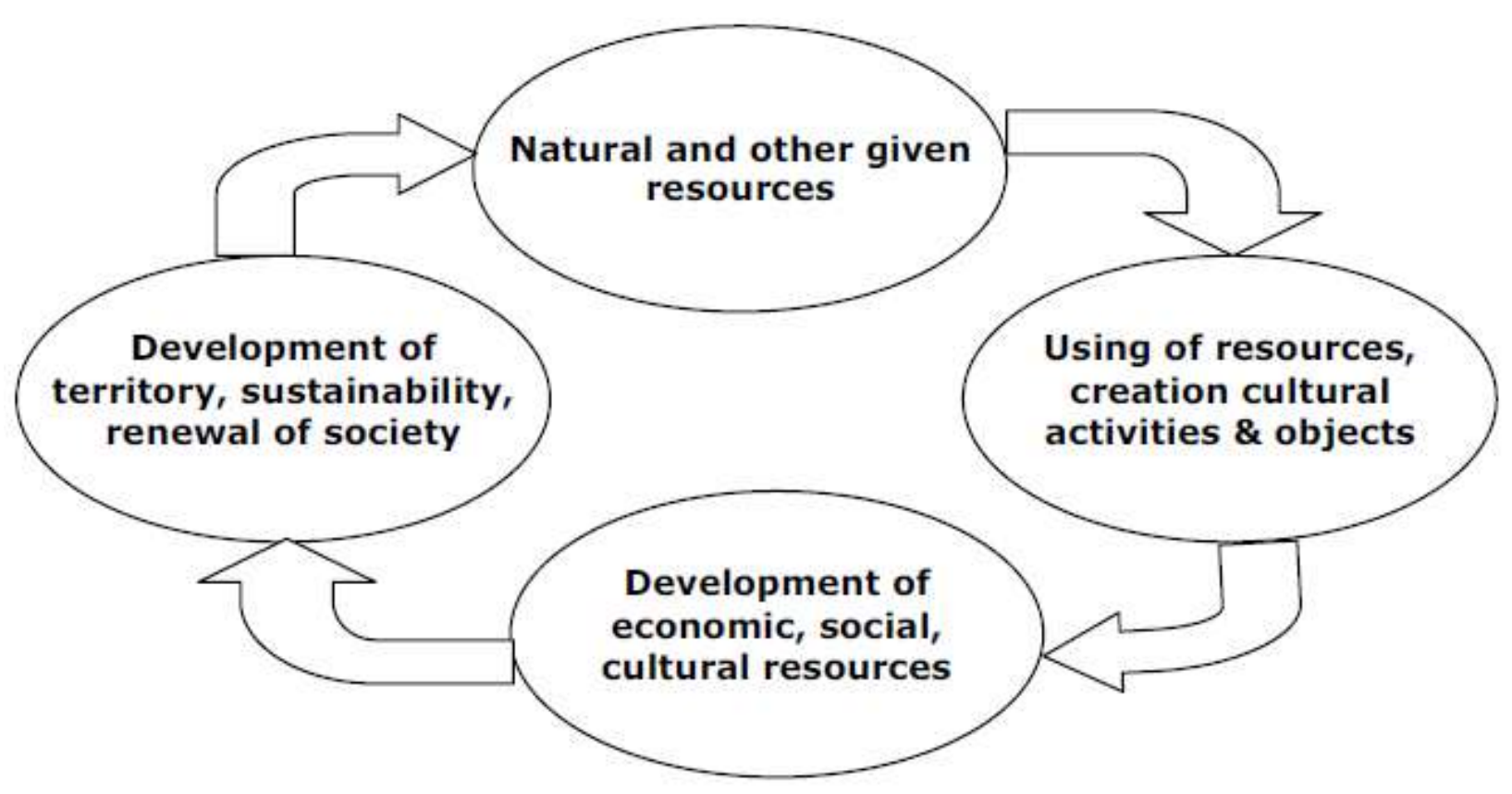

Figure 2: Cycle of development of cultural environment and its links with renewal of society

Source: Authors' construction based on theoretical statements

In the context of cultural environment, the sharing/exclusion and cooperation/competition dichotomies present especially interesting and challenging puzzles to a functionalist approach. It is so for three reasons. First, those who create, invent, innovate, and participate in similar intellectually driven, productive activities necessarily borrow from or share with others. It is impossible to divest oneself of that to which one has been exposed. Inevitably, the intellectual products of past and contemporary "producers" (refers to creators, inventors, innovators, thinkers, and the like) serve as inputs into productive activities. Second, the resources that shape the cultural environment are by their nature naturally non-rivalrous and no excludable, meaning that knowledge resources are not naturally defined by boundaries that permit the exclusion of users. Third, unlike resources in the natural world, resources of information and expression must be created before they can be shared. Because of the public goods character of these resources, a cultural commons must manage both use and production of cultural resources (Madison, Frischmann and Strandburg, 2010).

Consequently, the creation of culture includes different local actors, and everyone is invited in the creation and using of cultural and social benefits. Therefore, the question for public policy becomes how best to use legal and other tools to encourage the growth and persistence of creative, sustainable, and equitable cultural environments (Madison, Frischmann and Strandburg, 2010). To strengthen society, to promote the renewal of society in the context of balanced and sustainable development, the policy-makers develop strategies of the cultural environment. For instance, the Cultural Environment Strategy 2014-2020 of Finland practically emphasizes the same points as theorists: "The goals of the cultural environment strategy have been crystallized into three points of view: a valuable resource, sustainable development, and proper administration. A well- managed and vital cultural environment will enhance the well-being of people, and it is an important aspect of developing business activities and creating an attractive living environment. Systematic maintenance and enhancement of the cultural environment increase the vitality and attractiveness of areas, help to 


\section{Zenija Kruzmetra, Dina Bite, Ginta Kronberga \\ Cultural Environment as a Potential for Society Renewal}

implement sustainable development and sustain the values of the national heritage (Cultural Environment Strategy, 2014).

In the post-socialist countries, the growth of interest in the significance of cultural environment for the socio-economic development of local communities/local areas has been noticed only in recent years. Renewal of society is also a crucial point of reality of Latvia because of depopulation, territorial polarization, and shrinking processes during last decades.

Cultural Policy Guidelines 2014-2020 "Creative Latvia" mention that cultural diversity, richness, and accessibility, the participation of active and creative individuals in its development determine not only the quality of an individual's personality and his/her life but also the growth of society and nation. The Cultural environment is an environment that has been created as a result of human activities and retains their traces: both material and non-material values. Cultural heritage and cultural diversity are important conditions of sustainable and balanced development of the national territory. Each individual has a right to quality living environment (cultural environment) and obligation to care for its sustainability (Cultural Policy Guidelines, 2014, Development of Democratic, 2013). The significance of cultural environment in the development of territory is also confirmed by studies on this topic in Latvia: "Undeveloped or weak regional and local cultural policies and actions that are not able to incorporate the use of resources and opportunities of cultural environment in local development plans can be another reason for economically and socially active population to migrate away from the regions choosing traditionally strongest cultural centers as their residence" (Promotion of Diversity, 2008).

The aim of the article is to analyze cultural environment as a potential for renewal of society in rural territories of Latvia. The research tasks are related with a theoretical explanation of cultural environment and renewal of society and analysis of empirical materials collected by document analysis and semi-structured interviews. Research object is planning and development documents of local governments, different social agents of rural territories. The research questions are the following: How do local governments link the development of cultural environment to settlement patterns, population attraction, place development and renewal of society? How are these links reflected in planning and development documents of local governments and point of view of different social agents in rural territories?

\section{METHODOLOGY}

Authors use a qualitative approach to investigate the mentioned issues. The qualitative way of document analysis was done by analyzing current development strategies of four local governments and interviewing 45 different agents of local governments - local government officials, museum and tourist information center employees, small entrepreneurs, owners of farms and various service providers who in their activities use the natural and cultural heritage resources. This article analyzes the context of the following case study areas - Mazsalaca district, Kandava district, Sabile town, and Engure district. Main purposes of sampling were connected with territories of national importance (NATURA 2000, national parks), and territories with rich natural and cultural heritage in different regions of Latvia. The study was conducted during the period from March 2015 to August 2015.

\section{RESEARCH RESULTS AND DISCUSSION}

\subsection{Document analysis}

Qualitative analysis of development strategies of local governments discovers resources that local governments consider as their main foundation and property for development. Typically, local governments highlight natural resources, popular objects of tourism, and historic buildings in their territory. Description of these resources varies from general statements as "to preserve the traditional cultural landscape and only county-specific special living environment" to particular characteristics of existing resources. At the same time, the emphasis is put both on tangible and intangible cultural resources of local territory and community, for example, amateur art groups, various leisure activities, 
"environment characteristic to Latvia only", traditions and celebrations of local community, hospitality and strong families, etc. The awareness of existing resources is pretty high in analyzed documents, but not every local government appreciates their inhabitants as creators and maintainers of cultural environment.

Sometimes the list of cultural values seems "empty" because it is delimited from actual doers; there is no visible responsibility of any agent on maintaining of cultural and natural resources in policy documents. The opposite situation is seen in cases when local governments are aware of their inhabitants as a specific value; (they are patriotic, able to cooperate, creative, active, family-oriented, hospitable, educated, spiritually rich, loving their region, strong, resilient, responsive), perceive them as creators of development and supports their initiatives. Moreover, local governments present themselves as a formal institution that is responsible for organizing and giving opportunities for creating a cultural life and claim that the basis of further development is "residence and work shared and jointly created by entrepreneurs, institutes, farms, and fellowships". Thus, confirming cooperation and joint creation of their common living space. Also, there are different levels of awareness of formal goals in local municipalities.

Sometimes goals are general and even contradictive (e.g. a local municipality is proud of its current geographic and social apartness but in the future it would be a transit corridor); sometimes goals are clear and based on the real situation, actual needs, and specific values. The difference mentioned above in policy documents correlates with results found in interviews. Hypothetically, it means that awareness of local people as active agents in the creation of local community's life and awareness of clear aims serve as promoter of the development of the territory. Such way local government can create free space for private initiatives, social and cultural activities.

The interview results show different levels of understanding of the significance of cultural development in the development of territories, population attraction, population development and social renewal. Although, despite the distinct features, the interview results show that different activities creating cultural environment take place in all regions: cleaning of the area, preservation of natural and cultural heritage and promotion of new economic activities by creating new products using the natural resources, the creation of new tourism services, etc.

The interview results point out a problem that is linked to insufficient cooperation, lack of trust among social agents in counties and lack of understanding of common goals. The local government tries to implement a variety of initiatives but they are not consistent with and based on local people's needs and interests, so they do not gain public support. So, representatives of municipality discover: "we wanted to put together a catalog of vacant apartments it does not work here people do not want." In this case, the local government views the passivity and seclusion of its population as a hindrance for development but in essence, it reveals deeper problems linked to insufficiencies in the dialogue between local government and community, supporting initiatives of local people and learning their interests.

A vital prerequisite for public activation and promotion of trust is improving communication. A positive example is found is Seli (Mazsalaca district), where local administration specialists understand the mechanism of communication with the local population; they understand that people in rural areas must be addressed individually: "the hardest thing is finding contact. Afterwards people spread the word without pushing", as a result, people's activity sometimes exceeds all expectations, events are well attended. Such way people feel that they are welcome, that they are a vital part of the cultural environment of Seli.

Contrary experience is revealed by a public relations specialist of another district; she emphasizes low activity of local population but at the same time not even trying to find contact with more passive residents: "information can be found and read, it is open for everybody". Public discussions are poorly attended: "counties demonstrate a lack of responsiveness; we have 7-8 local officials and 3-4 inhabitants in the meeting" This specialist repeatedly shows an unwillingness to make the additional 
effort: "Do we have to go around and pin notes on each door?" This example demonstrates that public administration operates in isolation from the local community, which is considered as an obstacle to the smart development of the territory.

In the context of the study, authors highlight the narration of the head of Sabile Municipal Administration about the targeted actions of Talsi district officials to attract population, creating an attractive living environment not only for local residents but also visitors from Riga and other places purchasing a vacation home or entertain the idea of making a permanent residence in Sabile. He points out the necessity of creative thinking as a crucial prerequisite of any development: "We must think of how to attract people. People must be creative. Otherwise there is no production". Simultaneously, representatives of local government think of new products and services for both tourists and second home owners. Flats and houses are purchased by residents of Riga that want to have a second home, silent place, closeness to nature; also pensioners buy apartment avoiding city life. Currently, local government is working hard to build a new pre-school in Sabile to make the environment attractive to families with children because potential residents want their children to have good life: "If my child feels good, we choose this place for permanent residence". This example reveals sound and purposeful operation of the local administration to grow local population attraction.

Municipal staff is largely the ones who inspire local people to look for new solutions to economic and social problems. Even though the district head admits that "it was hard for me to accept that there will not be large production/factories in the area", he calls the locals not to despair but to take action: "through the craft associations, we offer the opportunity to produce and sell products. There are still lots of barriers in people's mind, but they slowly overcome them. One of them is a lack of motivation to work more and more productively".

The results of interviews show that local governments change their focus from economic determinism to social and cultural determinism gradually. Mostly it is caused by economic recession and depopulation processes in rural areas. The supply of free time activities is very wide and massive in Latvia. Hypothetically, cultural activities play the main role in the processes of renewal of society of Latvia, especially in places and territories where other resources (employment, access to different services) are lower. Quite often cultural activities are a way of surviving because of lack of working places. Rural people develop cultural and educational activities to attract tourists and to earn money, and it brings some changes in their lifestyle and also in the structure of the labor market in rural territories. Creation of culture is a certain way of surviving through which people quite often develop their small entrepreneurship (revitalizing of old traditions, celebrations, the teaching of new skills) that confirms existing of new social practices, social and economic innovations.

A successful example which represents private initiative is a family business "Maurini" that produces dried fish and offer the product tastings. It is located in the territory of Kemeri National Park. Members of this family implemented the idea of the renewal of Ragaciems sedums (cultural-historical facility for all the ancient fishing accessories) with their private resources, attracting residents and using existing natural resources, such as reeds from the Lake Kanieris. Other three young men from this village learned skills of thatched roof tiling. This is an example of how private initiative serves of creation new products without seeking out the assistance of local government but utilizing private funds and promoting the activity of local population. Now the renewed facility in Ragaciems hosts various events that are organized by the active part of the community. It is a good example of endogenous development as social and cultural aspects are more sustainable in long term perspective as they come from "bottom-up".

The analyzed local governments both in their development strategies and interviews confirm the importance of cultural environment as a potential of further development; they relate it to the development of settlement and population attraction. The difference is seen in their awareness of it and readiness to carry out these ideas practically and purposefully. Local governments need to find a balance between social, cultural, natural and economic issues of the territory. It is insufficient to 


\section{Zenija Kruzmetra, Dina Bite, Ginta Kronberga \\ Cultural Environment as a Potential for Society Renewal}

highlight clean air, historical buildings, and silence if it does not come together with adequate infrastructure.

Results show that developed cultural environment is like a catalyst that releases "free space" for local initiatives (according to Rudolf Steiner), quality of dialogue between public governance and local people, and participation of local people. However, it is not a fully evaluated and exploited potential. The development of cultural environment is important for every local government as it is a way how to activate local people, involve everyone and gradually develop social and economic structures. Local governments should play the main role in this process through developing of strategies and practical tools to support current local cultural initiatives and promote activity and participation of local people. Development of cultural environment can bring eventual changes in rural communities in a social and economic sense, but they are pretty fragile now. Therefore, they need support from local governments and national government.

\section{CONCLUSIONS, PROPOSALS, RECOMMENDATIONS}

1) Development of cultural environment now plays an important role both in the national and local development documents and local municipalities and citizens' daily life. Cultural activities generated and implemented in rural areas are a crucial resource for maintaining and attraction of local inhabitants, increasing of social capital and, as a result, renewal of society. The open question is what balance will be found between social, cultural, economic and environmental dimensions?

2) Massive development of cultural activities have both positive and negative connotations - on the one hand, cultural activities often are like desperation strategies for rural inhabitants, on the contrary - they can bring new social practices, innovations and serve as a transition to new social and economic structures.

3) The quantitative paradigm (economic growth, demographic increasing of the population) is gradually changing to qualitative paradigm (developing of human and social capital, assuming people as creating agents) informal strategies and practical actions of local governments. As a result of local activities, local governments tend to consider their inhabitants not so much as taxpayers, producers of goods or impersonal fillers but as a creative resource for innovative actions.

4) In general, local governments see the cultural environment as a potential for development of territory. However, there are different levels of awareness and practical action to promote and support local initiatives. Cultural activities have created original resources in rural territories of Latvia. The main task of local governments and inhabitants is to make cultural activities stronger, share them and make them available for everyone. Considering ideas of endogenous and smart development of territory, local governments should develop their own, unique strategy for development.

\section{REFERENCES}

- Concept Study on the Role of Cultural Heritage as the Fourth Pillar of Sustainable Development (2012). 73 pp.

- file:///E:/My\%20Documents/Downloads/Study+on+the+role+of+cultural+heritage+as+a+sus tainable+development + pillar-2.pdf, Access: 2.01.2016.

- Cultural Environment Strategy 2014-2020 of Finland (2014). Ministry of Education and Culture Ministry of the Environment, Helsinki.

- Demokratiska kulturpolitikas veidosana: kultura ka ilgtspejigas attistibas faktors Metodiskais materials kulturas organizacijam, pasvaldibu un valsts instituciju lemumu pienemejiem un sabiedribai, (2013). Development of Democratic Cultural Policies: Culture as a Factor in Sustainable Development. Methodological Material for Cultural Organizations, Local 


\section{Zenija Kruzmetra, Dina Bite, Ginta Kronberga}

Cultural Environment as a Potential for Society Renewal

Government and State Institutions Decision-Makers and the Public. Vidzemes kulturas un makslas biedriba "Haritas". Vidzeme Cultural and Art Association

- Duxbury, N., Jeannotte, M.S., (2012). Cities, Culture and Sustainable Development, Portugal. https://www.ces.uc.pt/myces/UserFiles/encontros/1097_DUXBURY_Torres_Vedras_05.09.201 2.pdf, Access:

- Grossi, E., Sacco, P.L., Blessi, G.T., Cerutti, R. (2011). The Impact of Culture on the Individual Subjective Well-Being of the Italian Population: An Exploratory Study. Applied Research in Quality of Life, Volume 6, Issue 4, pp 387-410, CrossRef

- Institute for Social Renewal, (2013). : http://socialrenewal.com/what-we-do/, Access: 21.12.2015.

- Kulturvides daudzveidibas veicinasana un parvaldiba: nevalstiskas un privatas kulturas iniciativas (2008).

- Promotion and Management of the Diversity of Cultural Environment: Non-governmental and Private Cultural

- Cornell Law Review, Vol. 95, p. 657, U. of Pittsburgh Legal Studies Research Paper No. 200826. : http://ssrn.com/abstract=1265793, Access: 9.12.2015.

- Matherne, B.. at al. (2005). A Book Review in A Reader`s Journal Vol.2,

- Smart Territorial Development, (2014). Investment Days. FAO. :

- Steiner, R. (2000). Towards Social Renewal, Rethinking the Basis of Society. :

- Valsts kulturpolitikas pamatnostadnes 2014.-2020.Gadam Radosa Latvija (2014) Cultural Policy Guidelines 2014

- Williams, N. (2008). The Source of Social Renewal. 